решается у нас в России созданием мегаватного ядерного двигателя [7].Еще больше перспектив у ядерных реакторов, в которых минуется тепловая фаза [4]. Эти двигатели много легче и более эффективны в эксплуатации, но и здесь нужны эксперименты, а их Роскосмосдаже не планирует.

Есть еще проблемы с запуском межпланетного космического корабля. Согласно международным договоренностям включать ядерные реакторы разрешается на орбитах не ниже 800км. Это означает, что сборку корабля придется вести на МКС из блоков, изготавливаемых на Земле, и доставлять на орбиту из любого нашего космодрома уже существующими ракетами. И уже готовый корабль запускать мощным разгонным блоком с околоземной орбиты. Но на МКС даже не помышляют о совместных конструкторских разработках, а торгуются с американцами о числе их астронавтов на борту и стоимости наших систем обслуживания их сегмента. Кто же тогда будет думать о будущем МКС? Только как о площадке репродукции героев России или как о стартовой площадке межпланетных полетов? Для начала хотя бы лунные модули надо научиться собирать на орбите: запускать с орбиты много дешевле! Но для этого надо переучивать на Земле космонавтов на конструкторские проблемы и менять всю программу подготовки астронавтов! А это нашим чиновникам хлопотно.

\title{
Заключение
}

Теоретически Россия готова лететь на Марс и далее к Звездам, но прогресс сдерживает бюрократический саботаж чиновников, считающих, что им необязательно выполнять указания президента РФ о модернизации космической отрасли[5].

$$
* * *
$$

1. Gerasimov E., Kichenko E. The Method of Stabilization of cerebral circulation in astronauts in conditions of weightlessness and aerospace overloads.//Norwegian journal of development of the international. No 10. 2017, p. 12-28.

2. Герасимов Е.М., Косарев А.В. Заявка на предполагаемое изобретение. №2017109925/11(017531) от 16.01.2017. «Способ реализации межпланетных сообщений и технические устройства для его реализации».

3. Демонстрационный электроплазменный двигатель, созданный $\mathrm{AO}$ «Конструкторское бюро Химавтоматика» [https:/geektimes.ru//post//276426-20.10.2016]

4. Косарев А.В. Тепловыделяющий элемент энергетического ядерного реактора. Патент РФ№122198 на полезную модель. Бюл. №32 от 20.11.2012. Приоритет от 25.05.2021.

5. Смирнов Дмитрий @dimsmirnov175. «Необходимо сохранить и преумножить позиции России в космосе» Режим доступа: (https://www.1tv.ru/news//2016/11/16/314129vladimir_putin_obsudil_s_predstavitelyami_pravitelstva_i_roskosmosa_perspektivy_razvitiya_kosmichesk oy_otrasli).

6. ЭлонМаск: «Земляне, которые отправятся на Марс первыми, должны быть готовы умереть». Колонисты поубивают друг друга. Режим доступа: http://www.ufa.kp.ru/daily/26587/3603305]

7. Ядерный космический двигатель-это полностью российский проект (http://www/nikiet.ru/index.php?option=com_content\$idview=articl\$id=426\%3A-2012-

280812 \$catid=Itemid=5).

\section{Кузьминова М.И. \\ Минеральное сырье Республики Саха (Якутия) для производства асфальтобетонов}

Северо-Восточный федеральный университет им. М.К. Аммосова

(Россия, Якутск)

doi:10.18411/spc-12-11-2017-14

idsp: 000001:spc-12-11-2017-14

Автомобильный транспорт любой страны является важнейшим элементом ее развития. По данным ежегодного информационно-статистического бюллетеня Министерства транспорта Российской Федерации из 9904,5 миллионов тонн различных грузов, перевезенных за 2014 год на долю автомобильного транспорта приходится более $50 \%(5414,4$ миллионов тонн). Аналогичная ситуация и с пассажирскими перевозками - на долю автомобильного транспорта приходится около $57,8 \%$ всех 
пассажирских перевозок. Состояние транспортно-дорожной сети в РФ, к сожалению, не может обеспечить постоянно растущие потребности страны, в связи с чем возникает угроза замедления развития отдельных секторов экономики. Из 1450348,3 км автомобильных дорог всего 1023000,2 км (70,5\%) имеют твердое покрытие, причем значительная часть из них имеет высокую степень износа и исчерпала свою пропускную способность, помимо этого, плохое качество дорожных покрытий сильно сказывается на безопасности передвижения транспортных средств по таким дорогам.

Наиболее распространенным материалом для строительства покрытий автомобильных дорог является асфальтобетон - рационально подобранная смесь минеральных материалов с битумом. Важнейшим структурообразующим элементом в асфальтобетоне является минеральный порошок (МП), что обусловлено его высокой удельной поверхностью по сравнению с другими минеральными материалами, входящими в состав асфальтобетона. Асфальтовяжущее вещество является бинарной системой, в которой битум выполняет роль дисперсной среды, а минеральный порошок - дисперсной фазы $[1,2]$. Высокая реакционная способность зерен минерального порошка позволяет переводить битум из объемного состояния в пленочное, что положительно сказывается на физико-механических свойствах битума: наблюдается повышение плотности, прочности, трещиностойкости, происходит улучшение теплостойкости.

По результатам ранее проведенных нами исследований было предложено и обосновано использование природных цеолитов и бурых углей в качестве минеральных порошков для производства асфальтобетонов. Доказано положительное влияние механоактивации минеральных порошков в планетарной мельнице на их структурирующие свойства по отношению к битуму. Полученные минеральные порошки и асфальтовяжущие вещества с их применением были испытаны в соответствии с ГОСТ 52129-2003 «Порошок минеральный для асфальтобетонных и органоминеральных смесей». Физико-механические характеристики минеральных порошков представлены в таблице $1 .[8,9]$

Таблица 1

Основные физико-механические свойства минеральных порошков

\begin{tabular}{|c|c|c|c|c|c|c|}
\hline \multirow[t]{2}{*}{ 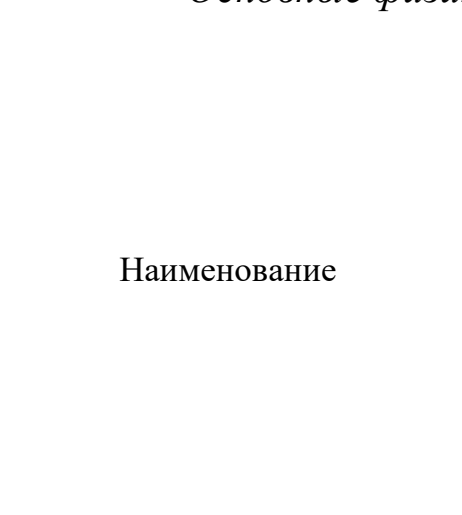 } & \multirow[b]{2}{*}{$\begin{array}{c}\text { Нормативные } \\
\text { показатели } \\
\text { минерального } \\
\text { порошка марки } \\
\text { МП-2 ГОСТ Р } \\
52129\end{array}$} & \multicolumn{5}{|c|}{ Минеральный порошок } \\
\hline & & $\begin{array}{l}\text { Известн } \\
\text { яковый } \\
\text { неактив } \\
\text { ированн } \\
\text { ый }\end{array}$ & $\begin{array}{c}\text { Из } \\
\text { приро } \\
\text { дного } \\
\text { цеоли } \\
\text { та }\end{array}$ & $\begin{array}{c}\text { Из } \\
\text { приро } \\
\text { дного } \\
\text { цеоли } \\
\text { та } \\
\text { актив } \\
\text { ирова } \\
\text { нный }\end{array}$ & $\begin{array}{l}\text { Из } \\
\text { бу } \\
\text { ро } \\
\text { го } \\
\text { уг } \\
\text { ля }\end{array}$ & $\begin{array}{c}\text { Из } \\
\text { бур } \\
\text { ого } \\
\text { угл } \\
\text { я } \\
\text { акт } \\
\text { иви } \\
\text { ров } \\
\text { анн } \\
\text { ый }\end{array}$ \\
\hline \multicolumn{7}{|l|}{ Зерновой состав, \% по массе } \\
\hline $\begin{array}{l}\text { Мельче 1,25 мм } \\
\text { Мельче 0,315 мм }\end{array}$ & $\begin{array}{l}\text { Не менее } 95 \\
\text { От } 80 \text { до } 95\end{array}$ & $\begin{array}{c}100 \\
90\end{array}$ & $\begin{array}{c}100 \\
90\end{array}$ & $\begin{array}{l}100 \\
100\end{array}$ & $\begin{array}{c}100 \\
90\end{array}$ & $\begin{array}{l}100 \\
100\end{array}$ \\
\hline Мельче 0,071 мм & Не менее 60 & 70 & 70 & 99,8 & 70 & 98,4 \\
\hline $\begin{array}{c}\text { Пористость, \% от объема } \\
\text { Набухание образцов из смеси } \\
\text { порошка с битумом, \% от } \\
\text { объема }\end{array}$ & Не менее 40 & 17,1 & 16,8 & 17,9 & $\begin{array}{l}23,1 \\
2,24\end{array}$ & 26,8 \\
\hline $\begin{array}{c}\text { Водостойкость образцов из } \\
\text { смеси порошка с битумом, \% } \\
\text { от объема }\end{array}$ & Не более 0,7 & 0,57 & 0,57 & 0,75 & 0,5 & 0,6 \\
\hline
\end{tabular}


Минеральные порошки из местного минерального сырья обладают более высокой пористостью, что в первую очередь связано с их строением. Также предложенные минеральные порошки характеризуются повышенным значением набухания, по сравнению с традиционно применяемым известняковым минеральным порошком, ввиду более развитой удельной поверхности зерен минерального порошка. Однако, данные показатели соответствуют требованиям нормативных документов, что позволяет применять их в качестве одной из составляющих частей асфальтобетонов.

В соответствии с требованиями ГОСТ 9128-2013 «Смеси асфальтобетонные, полимерасфальтобетонные, асфальтобетон, полимерасфальтобетон для автомобильных дорог и аэродромов» был подобран гранулометрический состав плотного асфальтобетона марки II типа Б. Кривая подбора зернового состава представлена на рисунке 1.

Приготовление асфальтобетонных смесей производилось при помощи лабораторного смесителя ЛС-АБ-10, формование образцов и их испытание - при помощи комплекса испытательных прессов ИП-1000М-авто и ИП-50М-авто, согласно ГОСТ 12801-98 «Материалы на основе органических вяжущих для дорожного и аэродромного строительства».

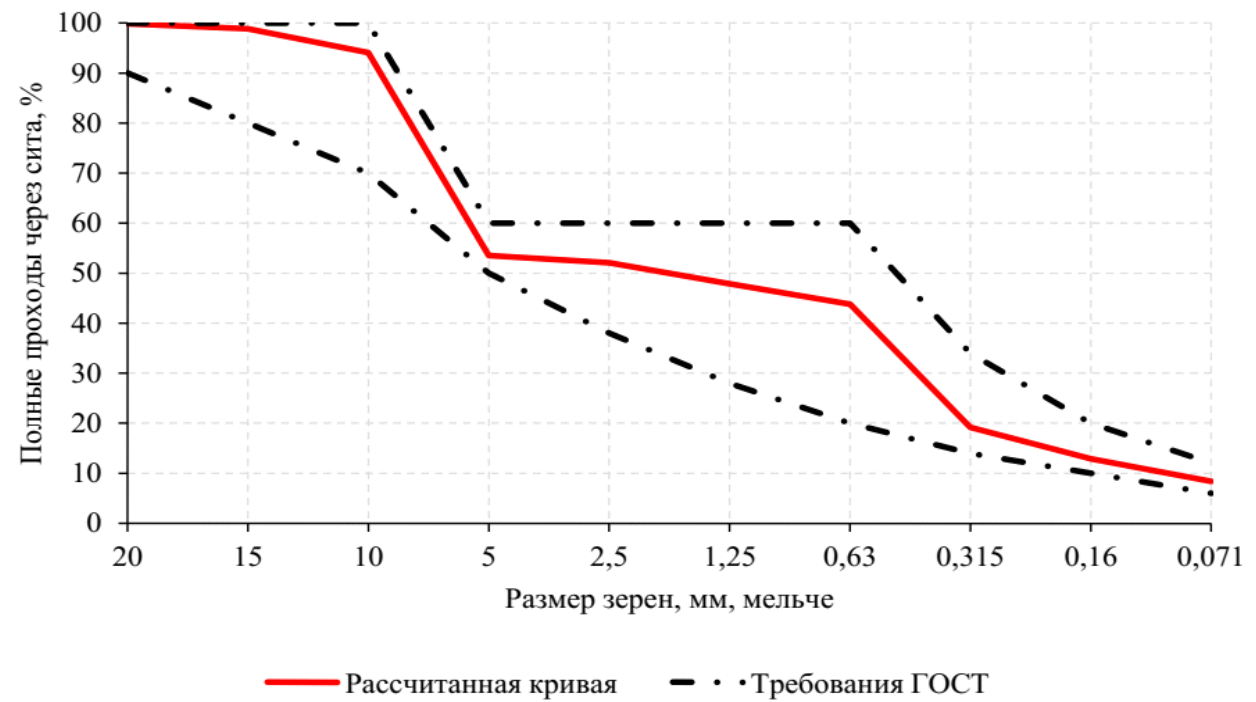

Рисунок 1. Зерновой состав минеральной части плотного асфальтобетона марки II, тип «Б»

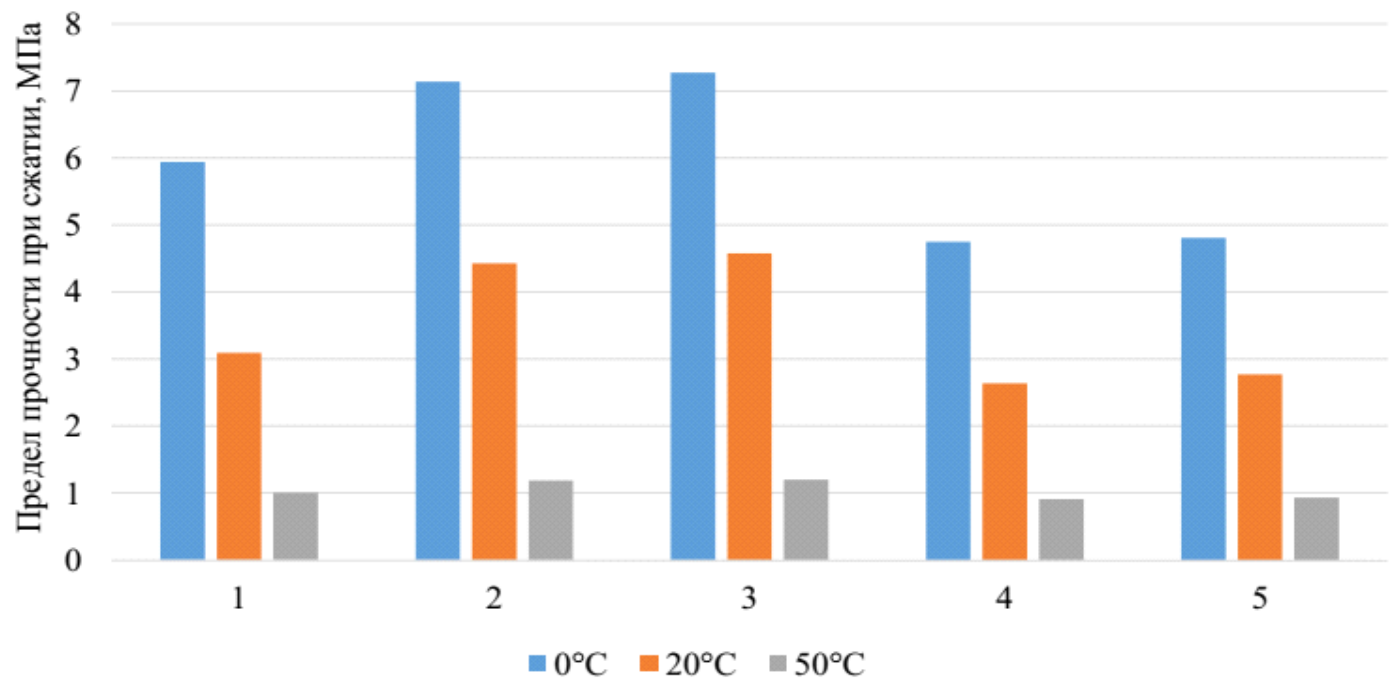

Рисунок 2. Предел прочности при сжатии асфальтобетонных образиов при температурах $0^{\circ} \mathrm{C}, 20^{\circ} \mathrm{C}$, $50^{\circ} \mathrm{C}$

1 - Асфальтобетон с известняковым МП; 2 - Асфальтобетон с МП из природного иеолита; 3 Асфальтобетон с МП из природного иееолта (активированный); 4 - Асфальтобетон с МП из бурого угля; 5 - Асфальтобетон с МП из бурого угля (активированньй) 
На рисунке 2 представлены результаты определения прочности при сжатии асфальтобетонных образцов при температурах $0^{\circ} \mathrm{C}, 20^{\circ} \mathrm{C}$ и $50^{\circ} \mathrm{C}$.

Анализ представленных данных показал, что образцы асфальтобетона с применением минерального порошка из природного цеолита обладают большими показателями предела прочности при сжатии. В среднем этот показатель возрастает на $30 \%$, а наибольший прирост прочности наблюдается у образцов, испытанных при $20^{\circ} \mathrm{C}$. Благодаря наличию на поверхности зерен минерального порошка оксидов металлов и развитой удельной поверхности, минеральный порошок из природного цеолита показал лучшую структурирующую способность по отношению к битуму, что положительно сказывается на прочности образцов. Снижение прочности асфальтобетонных образцов с применением бурого угля в качестве минерального порошка закономерно. Частицы минеральных порошков из бурых углей обладают преимущественно нейтральным зарядом, что хуже сказывается на их структурирующей способности. Помимо этого, низкая прочность бурых углей также снижает и прочность асфальтобетона. Однако, наблюдаемое снижение прочности при сжатии при $0^{\circ} \mathrm{C}$ может трактоваться как положительная характеристика асфальтобетона для регионов с холодным климатом, так покрытия из такого асфальтобетона будут дольше сохранять способность к релаксации после приложения нагрузки от колес автомобильного транспорта.

Помимо этого, для разработанных составов были определены основные физикомеханические характеристики, результаты представлены в таблице 2.

Таблица 2

Физико-механические характеристики асфальтобетонов

\begin{tabular}{|c|c|c|c|c|c|c|}
\hline \multirow[b]{2}{*}{ Наименование } & \multirow[b]{2}{*}{$\begin{array}{c}\text { Нормативные } \\
\text { показатели Марка } \\
\text { II тип Б ГОСТ } 9128\end{array}$} & \multicolumn{5}{|c|}{ Минеральный порошок } \\
\hline & & $\begin{array}{c}\text { Известн } \\
\text { яковый } \\
\text { неактив } \\
\text { ирован } \\
\text { ный }\end{array}$ & $\begin{array}{c}\text { Из } \\
\text { природ } \\
\text { ного } \\
\text { цеолит } \\
\text { а }\end{array}$ & $\begin{array}{c}\text { Из } \\
\text { природ } \\
\text { ного } \\
\text { цеолит } \\
\text { а } \\
\text { активи } \\
\text { рованн } \\
\text { ый }\end{array}$ & $\begin{array}{c}\text { Из } \\
\text { бурог } \\
\text { о угля }\end{array}$ & $\begin{array}{c}\text { Из } \\
\text { бурог } \\
\text { о } \\
\text { угля } \\
\text { актив } \\
\text { ирова } \\
\text { нный }\end{array}$ \\
\hline \multicolumn{7}{|l|}{$\begin{array}{c}\text { Предел прочности при сжатии, } \\
\text { МПа при температуре: }\end{array}$} \\
\hline $50{ }^{0} \mathrm{C}$ & Не менее 0,9 & 1,01 & 1,19 & 1,2 & 0,91 & 0,93 \\
\hline $20{ }^{0} \mathrm{C}$ & Не менее 2,2 & 3,09 & 4,43 & 4,58 & 2,64 & 2,77 \\
\hline $0^{0} \mathrm{C}$ & Не более 10 & 5,94 & 7,14 & 7,27 & 4,75 & 4,81 \\
\hline $\begin{array}{c}\text { Коэффициент } \\
\text { термостабильности }\end{array}$ & Не нормируется & 5,88 & 6,00 & 6,06 & 5,22 & 5,17 \\
\hline $\begin{array}{c}\text { Водостойкость } \\
\text { Сдвигоустройчивость }\end{array}$ & Не менее 0,9 & 0,93 & 0,97 & 0,96 & 0,97 & 0,96 \\
\hline $\begin{array}{c}\text { По коэффициенту внутреннего } \\
\text { трения }\end{array}$ & Не менее 0,8 & 0,81 & 0,9 & 0,95 & 0,87 & 0,84 \\
\hline $\begin{array}{c}\text { Сцеплению при сдвиге при } \\
\text { температуре } 50{ }^{0} \mathrm{C}, \mathrm{MПа}\end{array}$ & Не менее 0,31 & 0,94 & 0,86 & 0,80 & 0,81 & 0,81 \\
\hline Трещиностойкость, МПа & От 2,5 до 6,0 & 3,5 & 3,3 & 3,5 & 3,2 & 2,8 \\
\hline Водонасыщение & От 1,5 до 4,0 & 2,29 & 3,79 & 3,8 & 3,78 & 3,58 \\
\hline $\begin{array}{c}\text { Пористость минеральной части, } \\
\%\end{array}$ & От 14 до 19 & 15,5 & 15 & 15,4 & 15,7 & 15,7 \\
\hline
\end{tabular}

Повышение показателя предела прочности при сжатии независимо от температуры испытания по сравнению с традиционно применяемым известняковым минеральным порошком (таблица 2) доказывает, что минеральные порошки из природного цеолита оказывают лучшее структурирующее воздействие на битум. Ввиду строения и химического состава минеральных порошков из бурого угля, асфальтобетоны с их применением обладают меньшей прочностью. Однако, все разработанные составы асфальтобетонов с применением природного цеолита и бурого 
угля в качестве минеральных порошков полностью соответствуют требованиям ГОСТ 9128-2013.

$$
* * *
$$

1. Рыбьев, И.А. Асфальтовые бетоны. Учеб. пособие для строительных вузов. М., «Высшая школа», 1969. - $399 \mathrm{c}$.

2. Сахаров П.В. Способы проектирования асфальтобетонных смесей / П.В. Сахаров // Транспорт и дороги города. - 1935. - №12. - С. 22-26.

3. Копылов В.Е. Минеральные порошки из местного сырья для производства асфальтобетонов / В.Е. Копылов, О.Н. Буренина // Материалы для технических устройств и конструкций, применяемых в Арктике. Сборник докладов конференции. ФГУП ВИАМ. Москва, 2015. - С. 27.

4. Буренина О.Н. Возможности получения асфальтобетонных покрытий улучшенного качества в условиях холодного климата / О.Н. Буренина, Л.А. Николаева, В.Е. Копылов // Новые материалы и технологии в условиях Арктики. Материалы международного симпозиума. Северо-Восточный федеральный университет им. М.К. Аммосова. 2014. - с. 253

\section{Панайоти В.А., Бородин А.С., Замулаев К.И. \\ Выбор композиции твердой смазки для заточки инструмента из твердых сплавов}

Московский технологический университет (МИРЭА)

(Россия, Москва)

doi:10.18411/spc-12-11-2017-15

idsp: 000001:spc-12-11-2017-15

\section{Abstract}

In work the scope of solid lubricants is defined, the basic principles of creation of lubricant compositions are considered and zones of influence of the offered components are analysed and the mechanism of their influence on grinding process improvement is designated. Several compositions of solid lubricant are offered and tests when grinding supersolid material by diamond wheels in conditions of production are carried out when sharpening inserts of cutters from Elbora-ruble. Researches have shown efficiency of use of the solid lubricants applied in the course of grinding, have revealed extent of influence of its basis and fillers. The technique of a research of influence of composition of solid lubricant on processing is presented that allows to reveal its optimum structure in conditions of production.

Keywords: grinding, supersolid material, solid lubricant, a diamond wheel, composition of solid lubricant, an insert of cutters with a polycrystal elbora-R, chips and cracks.

Твердые смазочные материалы (ТСМ) находят все более широкое применение не только в узлах трения современных машин и механизмов, но и при абразивной и лезвийной обработке заготовок из широкой гаммы материалов. Их целесообразно применять, когда использование СОЖ затруднено или недопустимо, например, если применение жидких сред не достигает требуемого технологического эффекта или ее использование не обеспечивает безопасность работы оператора. Если к первым можно отнести обработку маломерных отверстий, нарезании резьбы в металлах, склонных к сильному налипанию, то ко второму: заточку режущего инструмента. При заточке лезвийных инструментов из быстрорежущей стали с применением твердой смазки имеются как лабораторные исследования, результатом которых является оценка смазывающей способности ТСМ $[1,2,3,4]$, его влияния на показатели процесса шлифования (силу и температуру резания), качество обработанной поверхности и расход абразивного круга $[5,6,7,8,9]$, так и опыт его производственного применения [10], Заточке же инструментов из твердых сплавов в условиях нанесения твердой смазки посвящено незначительное число публикаций. Поэтому в данной статье рассмотрены принципы разработки композиций твердой смазки для заточки инструментов из твердых сплавов, предложена методика исследования и представлены результаты производственных испытаний разных составов ТСМ . 